\title{
p53 Promotes Cytokine Expression in Melanoma to Regulate Drug Resistance and Migration
}

\author{
Pinakin Pandya *(D), Lyubov Kublo and Jacob Stewart-Ornstein * \\ Department of Computational and System Biology, Hillman Cancer Center \& University of Pittsburgh, \\ Pittsburgh, PA 15232, USA; LKUBLO@pitt.edu \\ * Correspondence: pip10@pitt.edu (P.P.); jacob@stewart-ornstein-lab.com (J.S.-O.)
}

check for

updates

Citation: Pandya, P.; Kublo, L.;

Stewart-Ornstein, J. p53 Promotes

Cytokine Expression in Melanoma to

Regulate Drug Resistance and

Migration. Cells 2022, 11, 405.

https://doi.org/10.3390/

cells11030405

Academic Editors: Ali R. Jazirehi,

Shikhar Mehrotra and

Negroiu Gabriela

Received: 1 November 2021

Accepted: 21 January 2022

Published: 25 January 2022

Publisher's Note: MDPI stays neutral with regard to jurisdictional claims in published maps and institutional affiliations.

Copyright: (c) 2022 by the authors Licensee MDPI, Basel, Switzerland. This article is an open access article distributed under the terms and conditions of the Creative Commons Attribution (CC BY) license (https:// creativecommons.org/licenses/by/ $4.0 /)$.

\begin{abstract}
The transcription factor p53 is frequently lost during tumor development in solid tumors; however, most melanomas retain a wild type p53 protein. The presence of wild type p53 in melanoma has fueled speculation that p53 may play a neutral or pro-tumorigenic role in this disease. Here we show that p53 is functional in human melanoma cell lines, and that loss of p53 results in a general reduction in basal NF-kB regulated cytokine production. The reduced cytokine expression triggered by p53 loss is broad and includes key inflammatory chemokines, such as CXCL1, CXCL8, and the IL6 class cytokine LIF, resulting in a reduced ability to induce chemotactic-dependent migration of tumor cells and immune cells and increased sensitivity to BRAF inhibition. Taken together, this result indicates that wild type p53 regulates cytokine expression and induces cytokine-dependent phenotype on melanoma.
\end{abstract}

Keywords: wild type p53; melanoma; NF-kB; cytokines; BRAF inhibitor

\section{Introduction}

The pleiotropic transcription factor p53 is a tumor suppressor that is frequently lost in human cancer development [1]. Some types of cancers, however, show relatively low p53 mutation rates. In melanoma, despite an extremely high average mutation burden, p53 is often retained, with only $\sim 20 \%$ of melanoma showing a mutation in p53 [2,3]. Further, these p53 mutations are not associated with reduced survival [4,5], and melanoma is relatively rare in families with germline p53 mutations [6,7]. These features of melanoma have fueled speculation that p53 may play a complex and potentially pro-tumor role in this cancer through the regulation of cell cycle arrest [8].

Previously, we observed that p53 could associate with cytokine genes such as IL1A and CXCL1 in certain melanoma cell lines [9], and other groups have shown an association between p53 status and cytokine secretion in fibroblasts [10] and macrophages [11]. This suggested to us that in melanoma p53 could potentially regulate-directly or in partnership with other factors-the expression of key immune-regulatory cytokines. As many cytokines regulate the local immune environment (e.g., pro-inflammatory cytokines) and promote proliferation through paracrine and autocrine signaling, this p53-regulated secretion could provide p53 wild type ( $\mathrm{p} 53^{\mathrm{WT}}$ ) melanoma cells with an advantage relative to their p53 loss-of-function ( $\mathrm{p} 53^{\text {lof }}$ ) counterparts. We therefore set out to test if loss of p53 would reduce the ability of melanoma cells to secrete cytokines and resist therapy.

In cancer cells, p53 can be inactivated by direct mutation or loss of the p53 gene or indirectly through perturbation of the p53 network $[12,13]$. We show that in four melanoma cell lines, treatment with DNA-damaging agents resulted in increased abundance of p53 and expression of classical downstream target genes. Loss of p53 in these cell lines resulted in reduced expression of p53 target genes, but also loss of NF-kB-regulated cytokines such as CXCL1. Indeed, multiplex cytokine measurements showed loss of several critical pro-inflammatory and pro-growth secreted cytokines including CXCL1, VEGF, LIF, and 
IL1. This loss of cytokine expression resulted in reduced ability to attract migrating cells and reduced intrinsic cellular fitness, including vulnerability to BRAF inhibitors.

\section{Materials and Methods}

\subsection{Cell Culture and Cell Treatment}

The UACC62, UACC257, LOX-IMVI, and SK-MEL-5 lines were grown in RPMI media (Gibco or VWR) $+10 \%$ FBS (Hyclone) $+1 \%$ PFS (Gibco) at $5 \% \mathrm{CO} 2$ at $37^{\circ} \mathrm{C}$. All cell lines were obtained from ATCC, and with the exception of the hTERT-immortalized melanocytes, all have been previously verified by string profiling. The hTERT-immortalized melanocytes were obtained from ATCC and were grown in the human melanocyte cell culture system (GIBCO-medium 254 supplemented with human melanocyte growth supplement) at $5 \%$ $\mathrm{CO} 2$ at $37^{\circ} \mathrm{C}$.

Cells were treated with Nutlin-3A ( $5 \mu \mathrm{M}$, Sigma from a stock concentration of $10 \mathrm{mM}$ in DMSO), etoposide ( $25 \mu \mathrm{M}$, Sigma, stock of $50 \mathrm{mM}$ in DMSO) as indicated. For UV treatment cells were switched from normal medium to DPBS (Gibco) and exposed to UVC $\left(254 \mathrm{~nm}, 10 \mathrm{~J} / \mathrm{m}^{2}\right)$ using a mounted UV lamp; the media was subsequently replaced with fresh warm media, and the cells returned to the incubator for the indicated period of time.

For the stimulation experiment, melanoma cells were treated with $0.1 \mu \mathrm{g} / \mathrm{mL}$ recombinant Wnt5a (r-Wnt5a, R and D from a stock concentration of $10 \mu \mathrm{g} / \mathrm{mL}$ in phosphatebuffered saline containing $0.1 \%$ bovine serum albumin) for $16 \mathrm{~h}$ in serum-free medium or incubated with $10 \mathrm{ng} / \mathrm{mL}$ TNF-alpha (TNF- $\alpha$, from stock concentration of $50 \mu \mathrm{g} / \mathrm{mL}$ ) for the indicated time in complete medium.

To collect supernatants, p53 wild type (p53 $3^{\mathrm{WT}}$ ) and knockout $\left(\mathrm{p} 53^{\mathrm{ko}}\right)$ melanoma cells were seeded in $35 \mathrm{~mm}$ dishes $\left(1 \times 10^{5}\right.$ cells/dish $)$ or in $100 \mathrm{~mm}$ culture dishes $\left(8 \times 10^{5}\right.$ cells $/$ dish $)$ in complete media and cultured for $48 \mathrm{~h}$ at $37^{\circ} \mathrm{C}$ and $5 \% \mathrm{CO} 2$-incubator. Culture media was harvested, centrifuged at $1000 \times \mathrm{g}$ for $10 \mathrm{~min}\left(4^{\circ} \mathrm{C}\right)$, filtered and stored at $-20^{\circ} \mathrm{C}$. For Transwell migration assay, medium was replaced with serum-free medium, and culture dishes were kept in incubator for $24 \mathrm{~h}$ before harvesting supernatants.

To induce p53 expression in knockout cell lines, we infect UACC62 cells with p53-GFP cloned into a FUGW-puro lentiviral vector (FU-H2B-GFP-IRES-Puro was a gift from Charles Gersbach (Addgene plasmid \# 69550; http:/ /n2t.net/addgene:69550; RRID:Addgene_69550)) (accessed on 18 April 2019). The p53 sequence was cloned in place of the H2B sequence after digestion with XBA1 and AGE1.

\subsection{Reagent and Antibodies}

Nutlin-3A was from Sigma-Aldrich(St. Louis, MO, USA). Recombinant Wnt5a and human TNF- $\alpha$ was obtained from R \& D system (Minneapolis, MN, USA)and Peprotech (Cranbury, NJ, USA) respectively. Mouse monoclonal antibodies for p53 protein (DO-1), $\beta$-actin (MA1-140) and rabbit monoclonal Abs for phospho-ERK1/ERK2 (Thr185, Tyr187) (700012) were from Thermo Fisher Scientific Technology (Waltham, MA, USA). Rabbit monoclonal antibodies for NF-kB p65 (8242) were from Cell Signaling Technology Inc. (Danvers, MA, USA). Rabbit polyclonal antibodies against N-terminal PARP1 (39559) was from Active Motif (Carlsbad, CA, USA). APC-conjugated mouse monoclonal anti-NF-kB p65 was obtained from BioLegend (San Diego, CA, USA). Infrared (IR)-conjugated goat antimouse (IRDye 680) and goat anti-rabbit (IRDye 800) were from LI-COR Bioscience (Lincoln, $\mathrm{NE}, \mathrm{USA}$ ). NucBlue ${ }^{\mathrm{TM}}$ live cell staining reagent was from Invitrogen Bioscience (Waltham, MA, USA). Puromycin $(10 \mathrm{mg} / \mathrm{mL})$, blasticidin $(10 \mathrm{mg} / \mathrm{mL})$ and $\mathrm{G} 418$ antibiotic solution were from Biovision (Milpitas, CA, USA) and VWR life science (Bridgeport, NJ, USA), respectively.

\subsection{Lentiviral Production and Infection}

The human embryonic kidney cells (HEK-293Tx) were seeded into a $60 \mathrm{~mm}$ culture dish (5 $\times 10^{5}$ cells $/$ dish). At 70-80\% cell confluency, constructs were co-transfected into HEK-293Tx cells together with three plasmids encoding Gag, Pol, Rev and VSVG (third 
generation virus production system) using transIT-LT1 transfection reagent (Mirus, Madison). Next day, the reagent containing medium was replaced with fresh complete medium. After $24 \mathrm{~h}$ incubation, viral supernatant was collected, centrifuged at $800 \times g$ for $10 \mathrm{~min}$, filtered through a $0.45 \mu \mathrm{m}$ filter, and stored at $-80^{\circ} \mathrm{C}$ or used immediately. Melanoma cells, which were plated on the previous day and reached a 50-60\% confluency level, were infected by the addition of viral supernatant. $24 \mathrm{~h}$ after infection, the media was removed, cells were washed once and supplied with complete medium containing selection agents.

\subsection{Generation of $p 53^{k o}$ Lines}

LOX-IMVI and SK-MEL-5 cell lines were infected overnight with Cas9-blast (gifts from John Doench \& Willian Hahn \& David Root (Addgene plasmid \#96924) virus. Then, cells were washed once with PBS-1X and supplied with fresh complete culture media containing blasticidin $(10 \mu \mathrm{g} / \mathrm{mL}$, Biovision). The selection process was continued for one week by delivering fresh medium with antibiotic every 2 or 3 days. Cells expressing Cas 9 were verified by Western blot, and frozen down as a poly-clonal population.

Melanoma cells expressing Cas9 were infected with guide RNA expressing virus (lentiGuide-Puro was a gift from Feng Zhang (Addgene plasmid \# 52963; http: / / n2t.net/ addgene:52963; RRID:Addgene_52963) (accessed on 14 October 2019), guide sequence ATCTGACTGCGGCTCCTCCA) that is targeting the n-terminus of the endogenous p53 sequence or non-targeting sequence (GTATTACTGATATTGGTGGG) as a control. Next day, cells were washed once with PBS- $1 \mathrm{x}$, the media was replaced by puromycin $(1.5 \mu \mathrm{g} / \mathrm{mL}$, Invitrogen) containing complete RPMI media, and the selection process continued for 3 days. Antibiotic-resistant cells were isolated and cloned through limiting dilution in 96-well plates. After the clonal expansion step, the p53 protein expression was determined by Western blot analysis, and individual clones with no p53 protein expression were considered as knockout clones.

UACC62 and UACC257 cells were transfected with cas9-guide RNA plasmid with a guide targeting p53 (pX330-U6-Chimeric_BB-CBh-hSpCas9, ATCTGACTGCGGCTCCTCCA) using transIT-LT1 transfection reagent. Transfected cells were treated with Nutlin3A $(5 \mu \mathrm{m})$ for 7 days, followed by single-cell cloning by limiting dilution to obtain p53 knockout clones. $\mathrm{p} 53^{\mathrm{ko}}$ cell lines were confirmed by immunoblot analysis.

\subsection{Preparation of Cellular Lysates and Western Blotting}

Cells were resuspended in a lysis buffer $(50 \mathrm{mM}$ tris $\mathrm{pH} 7.5,100 \mathrm{mM} \mathrm{NaCl}, 1 \%$ Triton X-100, $0.5 \%$ sodium deoxycholate, $0.1 \%$ sodium dodecyl sulfate combined with protease and phosphatase inhibitor cocktail [Halt ${ }^{\circledR}$ protease and phosphatase cocktail, Thermo]) followed by $30 \mathrm{~min}$ incubation on ice and centrifugation at $13,000 \mathrm{rpm}$ for $30 \mathrm{~min}$ at $4{ }^{\circ} \mathrm{C}$. Cleared supernatant was collected and stored at $-80^{\circ} \mathrm{C}$. The collected supernatant was quantitated using the Bio-Rad protein assay reagent (Bio-Rad, Hercules, CA, USA).

Protein lysates (equivalent to 15 to $25 \mu \mathrm{g}$ protein) were combined with loading dye and reducing agent (DTT), followed by vortexing and kept at $95{ }^{\circ} \mathrm{C}$ for $5 \mathrm{~min}$. The boiled protein samples were resolved on 4-12\% Bis-tris gradient gel (Invitrogen) and transferred onto $0.4 \mu \mathrm{M}$ nitrocellulose membrane. The membrane was blocked using 3\% BSA in $0.1 \%$ tween-20 containing tris-buffered saline, and incubated with primary antibodies overnight at $4{ }^{\circ} \mathrm{C}$. After washing three times with TBST- $1 \mathrm{x}$ ( $5 \mathrm{~min}$ for each washing step), membrane was incubated with IRDye conjugated goat anti-mouse or anti-rabbit secondary antibodies for $1 \mathrm{~h}$ in the dark at RT, and immunoreactive protein bands were detected using a typhoon imaging system (Amersham, GE, USA).

The primary antibodies used were as follows: anti-p53 (1:1000), anti-actin (1:1000), anti-pERK1/pERK2 (1:1000), anti-p65 (1:1000) and anti-PARP1 (1:1000) in blocking solution ( $3 \%$ BSA in $0.1 \%$ tween -20 containing TBS- $1 \mathrm{X}$ ). 


\subsection{RNA Extraction and $q P C R$}

Melanoma cells were seeded in a $35 \mathrm{~mm}$ dish and cultured at $37^{\circ} \mathrm{C}$ and $5 \% \mathrm{CO} 2$ incubator. They were collected in Trizol at a $70-80 \%$ confluency point. Total RNA was extracted using the direct zol RNA kit (Zymo Research Corp, Irvine, CA, USA) according to the manufacturer's instructions. qPCR was performed on a Quantstudio3 (Thermo). Total RNA (typically $100 \mathrm{ng}$ ) was reverse transcribed using the LunaScript RT super mix (NEB, Ipswich, MA, USA) and CDNA was diluted 10-fold. Each PCR reaction was run as technical duplicates or triplicates using $5 \mu \mathrm{L}$ of Luna Universal qPCR master mix (NEB), $1 \mu \mathrm{L}$ of each $2.5 \mu \mathrm{M}$ primer, and $3 \mu \mathrm{L}$ of diluted cDNA. The PCR program was run according to the manufacturer's suggestions and quantification was done using the quantstudio software. Subsequent analysis of qPCR ct values was performed in Prism (Graphpad), normalizing to ACTB expression.

Primers used are as follows

ACTB: ACCTTCTACAATGAGCTGCG, CCTGGATAGCAACGTACATGG

IL1A: TGTATGTGACTGCCCAAGATG, TTAGTGCCGTGAGTTTCCC

II1B: ATGCACCTGTACGATCACTG, ACAAAGGACATGGAGAACACC

CXCL1: AACCGAAGTCATAGCCACAC, CCTCCCTTCTGGTCAGTTG

CXCL8: AGGGTTGCCAGATGCAATAC, AAACCAAGGCACAGTGGAAC [14]

LIF: CCAGATCAGGAGCCAACT, CCAAGGTACACGACTATGC [15]

IL6: CAGTTCCTGCAGAAAAAGGCAA, AGCTGCGCAGAATGAGATGA [16]

WNT5A: ATTCTTGGTGGTCGCTAGGTA, CGCCTTCTCCGATGTACTGC [17]

TNFAIP3: CTGCCCAGGAATGCTACAGATAC, GTGGAACAGCTCGGATTTCAG [18]

P65: AATGGCTCGTCTGTAGTGC, TGCTCAATGATCTCCACATAGG

NF-kB1: GAAAAGCTGTAAACATGAGCCG, ACCCTGACCTTGCCTATTTG

\subsection{TCGA Analysis}

Data from the Pan-Cancer Atlas [19] were downloaded from cBioPortal [20,21]. The following datasets were used from the TCGA Pan-Cancer Atlas [22]: "skcm_tcga_pan_can_atlas_2018". The "data_RNA_Seq_v2_expression_median" was extracted to measure gene expression and the "data_mutations_extended" was used to identify tumors with a p53 mutation, defined as the presence of any mutation in p53 that was not classified as 'silent' or ' 3 'UTR'. Tumor IDs between RNA and DNA data were then matched, and the gene expression profiles were sorted into p53 wild type or p53 mutant. From this data, the expression of each gene in the dataset was compared between the p53 mutant and wild type groups of tumors with a KStest. Genes were then sorted by their significance and sign of effect (e.g., from most to least significant for up- and down-regulated genes) and genes with less than an average FPKM (fragment per kilobase of transcript per million base read) of 2 were discarded. Gene set enrichment analysis was obtained from the GSEA2 Gene Set Enrichment Analysis (GSEA) function in MATLAB [23].

\section{8. $m$ RNA Sequencing and Analysis}

Total RNA was extracted from cells using trizol (thermo) and DirectZol miniprep kit (Zymo). RNA (500 ng) was used to generate libraries using the Ultra II mRNA seq kit with poly-a selection (NEB), following the manufacturer's protocols. Libraries were quantified with qPCR (NEB library quant kit) and sequenced on a Nextseq500 with $1 \times 75$ bp reads. Samples were obtained and libraries generated in biological duplicates. Reads were aligned to the Hg19 refseq transcripts using Salmon V0.7.2 [24], and reads were aggregated from transcript to genes. Gene read tables were subsequently compared using Deseq2 [25]. Heatmaps and gene intersections were generated with MATLAB or R.

Gene set enrichment analysis was obtained from the GSEA2 Gene Set Enrichment Analysis (GSEA) function in MATLAB [26]. Genes were sorted by fold change in expression after applying cutoffs for minimal expression ( $>25$ read counts). Where groups of genes were obtained rather than ranked lists (e.g., overlapping gene sets across multiple cell types [Figure 1] or multiple knockouts [Figure 2]), a simple hypergeometric test was 
used to obtain enrichment for different Hallmark gene sets using the Broad/UCSC web server [26-28].

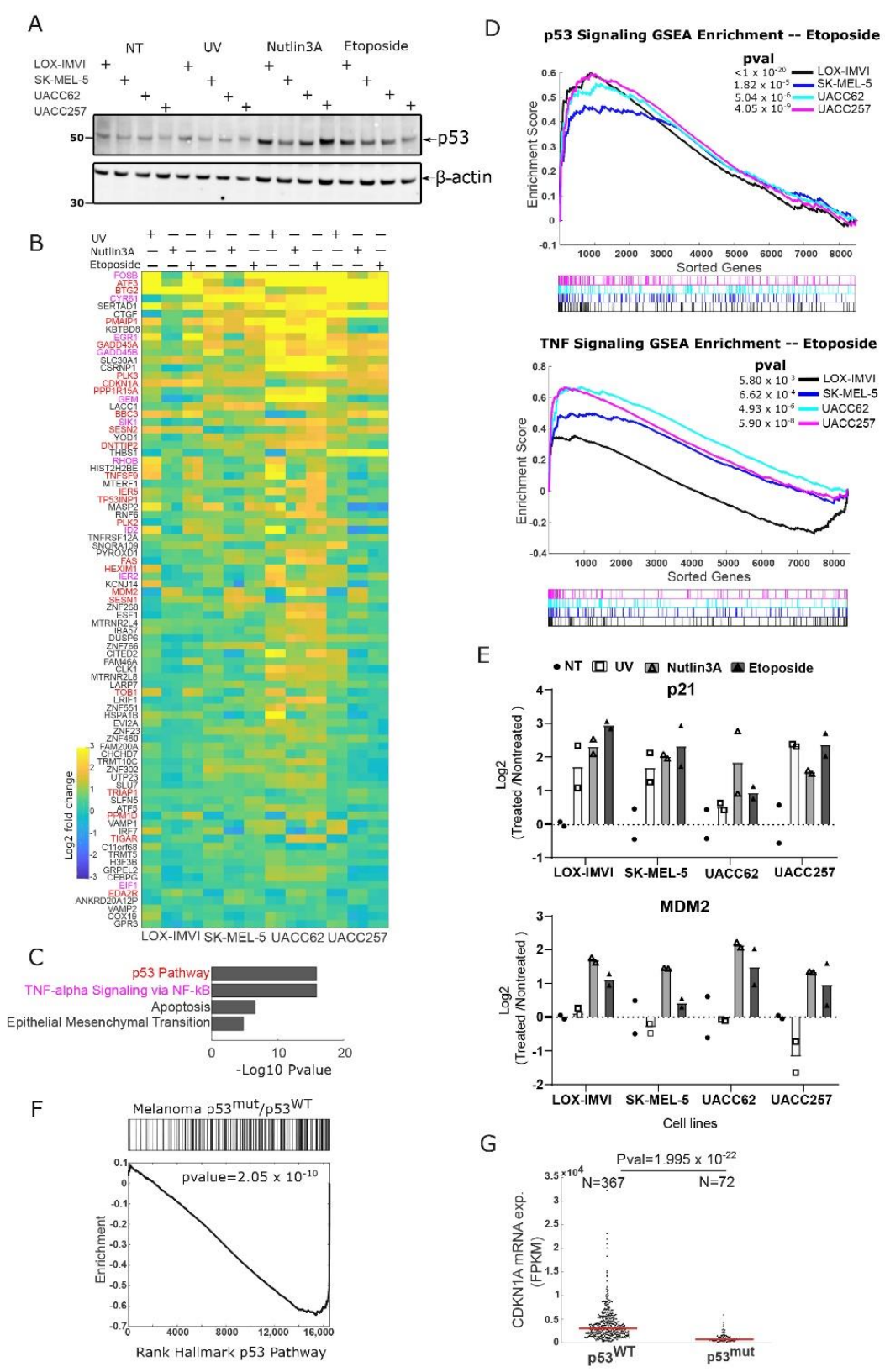

Figure 1. Melanoma cell lines show active p53 signaling on stress. (A) Four human melanoma cell lines were not treated (NT) or treated with UV $\left(10 \mathrm{~J} / \mathrm{m}^{2}\right)$, etoposide $(25 \mu \mathrm{M})$, or Nutlin-3A $(5 \mu \mathrm{M})$ for three hours. Western for p53 with $\beta$-actin as a loading control. (B) Heatmap showing changes in gene expression for each cell line after $3 \mathrm{~h}$ of UV, Nutlin-3A, or Etoposide treatment (as in A). Genes whose expression changed in each cell line by at least 1.5 -fold in one or more conditions are shown, sorted by average fold change ( $n=2$ for each cell line/treatment). Gene symbol color indicates p53 pathway (red) or NF-kB pathway (purple). (C) Gene set enrichment of genes shown in Figure 1B using Hallmark gene sets. (D) Gene set enrichment analysis of each cell line for the p53 and TNF signaling pathways for etoposide treatment. (E) qPCR data showing the activation of p53 target p21 and MDM2 in the indicated conditions; $n=2$. (F) Gene set enrichment analysis of Gene expression from human melanoma tumors (TCGA samples) comparing tumors with mutant p53 to those with wild type p53. (G) mRNA expression of p53 target gene CDKN1A (p21) in human melanoma samples stratified for p53 wild type and p53 mutant alleles; data are mRNAseq collected by The Cancer Genome Atlas (TCGA); units are in fragment per kilobase of transcript per million reads (FPKM). 
A

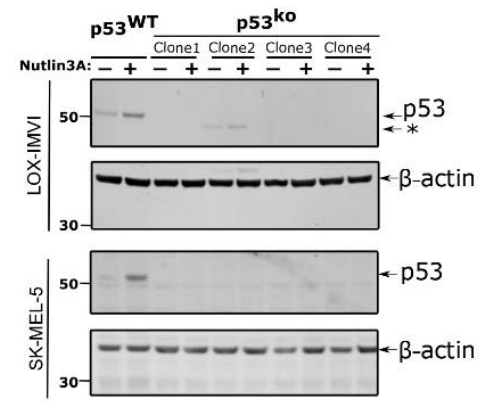

C

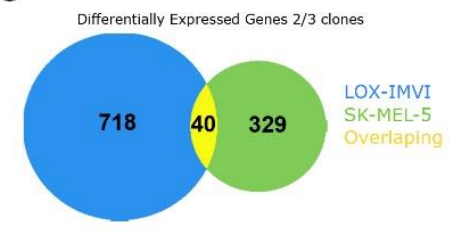
Common genes altered in
LOX-IMVI and SK-MEL- 5 p53 ${ }^{\mathrm{ko}}$ clones $\quad D$ EDA2
PTCHD
ANKRD20A12 MIR34A

TP
TP53IN
LOC1027237
CDKN
COL5A

COL5A
PHLDA
NFATC2

NFATC2
GDF15
DDB

DDB2
TMEM158
RPS271

RPS27L

FLRT2
NNMT

NNMT
CXCL1

SVIL
FDXR

JAG1
NAMPT

DNER

ZMAT3

MNN
TGFBP
BCYRN

BCYRN1
CAV1
KYNU
KLFG

KYN
KLF
TSC22D
PRSS2

PRSS23
CKAP4
FRMP

FRMD6
NFRSF10B
BAX

BAX
SH3PXD2B

SEC14

$\mathrm{Cl}_{1} \mathrm{C}_{2} \mathrm{C} 3 \mathrm{Cl}_{1} \mathrm{C}_{2} \mathrm{C} 3$

OX-IMVI SK-MEL-5
B

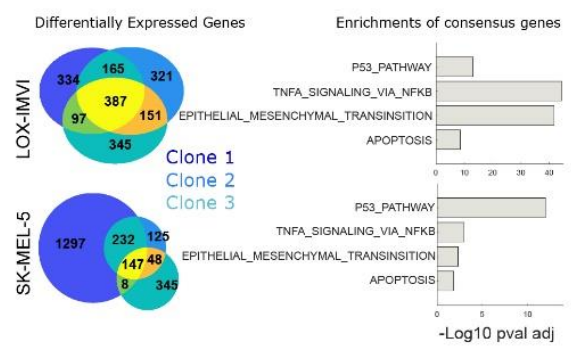

p21

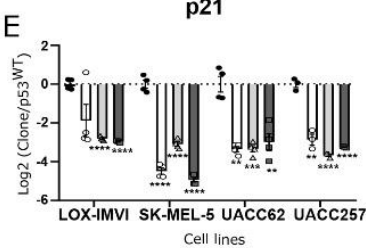

- $\mathrm{p} 53 \mathrm{WT}$

\begin{tabular}{l|l}
$\triangle$ \\
$\triangle$ Clone2
\end{tabular}

$\square$ Clone3

CXCL1

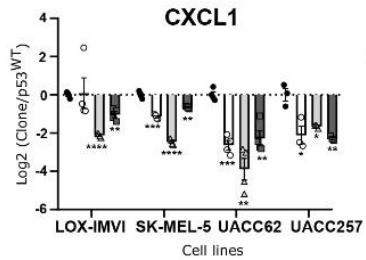

${ }^{4} \quad$ CXCL8

LIF

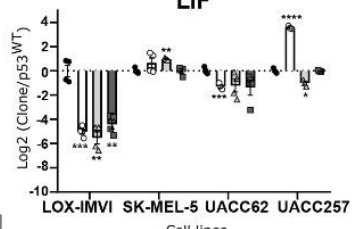

Cell lines

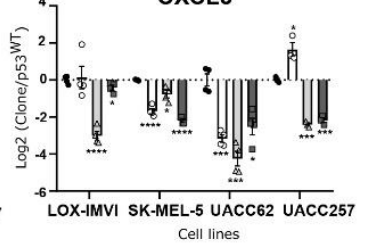

WNT5A

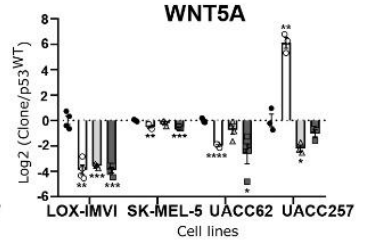

- GFP

- GFP.p53

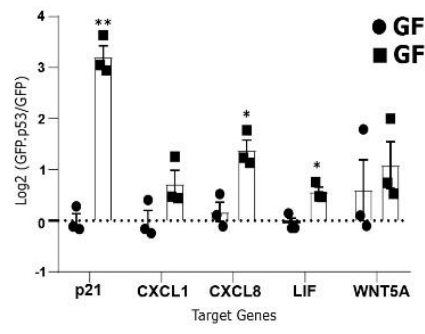

Figure 2. Loss of p53 in melanoma cells results in pleiotropic effects. (A) Validation of p53 knockout clones from two cell lines by Western blot. (B) Comparison of differentially expressed genes from three p53 knockout clones from LOX-IMVI and SK-MEL-5, enrichment analysis using hallmark gene sets of the overlapping genes from each cell line. (C) Differentially expressed genes from each cell line in at least 2/3 p53 knockout clones were identified; expression of each overlapping gene relative to wild type is shown in a heatmap ( $n=2$ for each sample). (D) Gene set analysis of overlapping gene set from (C). (E) qPCR validation of changes in TNF/NF-kB signaling, focusing on a set of key cytokine targets in p53 knockout cells from four melanoma cell lines, $n=4$, except UACC257 where $n=3$ (mean \pm S.E.M.). (F) Expression of wild type p53 in UACC62 p53 ${ }^{\mathrm{ko}}$ increases expression of p53 target gene p21 and also of cytokine genes identified in (D), $n=3$ (mean \pm S.E.M.). Individual biological samples in (E,F) are represented by a square or circle. Asterisk $\left(^{*}\right)$ in (A) denotes the lower molecular weight band in one of the LOX-IMVI clones. Significance was determined by $t$-test in compared to wild type in (E) or to GFP in (F) group, and observed significance level is denoted by an asterisk $\left({ }^{*}<0.05 ;^{* *}<0.005 ;{ }^{* * *}<0.0005 ;{ }^{* * * *}<0.0001\right)$. 


\subsection{Si-RNA Mediated Gene Silencing}

Gene silencing using a mixture of 4 different siRNAs targeting Wnt5a (L-003939-000005), p65 (L-003533-00-00005) or non-targeting control (D-001810-01-05) were received from Dharmacon Inc. (ThermoFisher Scientific, Waltham, MA, USA). Transfection steps proceeded as per manufacturer instruction. Briefly, cells $\left(5 \times 10^{4}\right.$ cells/well) were seeded in 12-well plates and cultured for overnight. Adherent cells were transfected using mixture of si-RNA $(5 \mathrm{~nm})$ and dharmafect transfection reagent $(2.5 \mu \mathrm{L} /$ well $)$ in reduced serum media (Opti-MEM). $48 \mathrm{~h}$ post-siRNA delivery, cells were collected in trizol and utilized for gene expression analysis by qRT-PCR.

\subsection{Transwell Migration Assay}

Transwell migration assay was performed in a Boyden chamber containing polycarbonate filters with $8 \mu \mathrm{m}$ pore size (costar, Bodenheim, Germany). LOX-IMVI cells were harvested by trypsin for $2 \mathrm{~min}$ and mixed with defined trypsin inhibitor (cascade biologics, ThermoFisher Scientific) in a ratio of 1:1. The Transwell upper compartment was loaded with $100 \mu \mathrm{L}$ cellular suspension $\left(6 \times 10^{5}\right.$ cells $/ \mathrm{mL}$ in serum-free media), whereas the lower compartment was filled with supernatant $(600 \mu \mathrm{L})$ that was collected from $\mathrm{p} 53^{\mathrm{WT}}$ or $\mathrm{p} 53^{\mathrm{ko}}$ melanoma cells or serum-free culture medium for negative control. After incubation at $37^{\circ} \mathrm{C}$ and $5 \% \mathrm{CO} 2$-incubator for $24 \mathrm{~h}$, Transwell filters were removed, fixed using $4 \%$ PFA for $15 \mathrm{~min}$ at RT, and stained by NucBlue Live stain reagent (Invitrogen) for $1 \mathrm{~h}$. Transwell images were photographed by LionHeart/FX automated microscope (BioTek, Santa Clara, CA, USA), and total migrated cells in each well were counted by Fiji image J software.

For U-937 cell migration assay, cells $\left(1 \times 10^{6} / \mathrm{mL}\right)$ were suspended in serum-free medium, and $100 \mu \mathrm{L}$ cellular suspension was loaded into the upper compartment. The lower compartment was filled with $600 \mu \mathrm{L}$ p53 $3^{\mathrm{WT}}$ or p $53^{\mathrm{ko}}$ supernatant or serum-free culture medium. After incubation at $37^{\circ} \mathrm{C}$ and $5 \% \mathrm{CO} 2$-incubator for $24 \mathrm{~h}$, Transwell filters were removed and cells in lower compartment were counted using Cellometer (Nexcelom Bioscience, Lawrence, MA, USA).

\subsection{Cytokine Expression Analysis}

Tumor cells supernatants were collected as mentioned before. Human CXCL1 expression was analyzed using Elisa set (R \& D system, DY 275), according to company instruction. The culture supernatants were assayed at a dilution within the linear range of the CXCL1 standards, and the concentration of CXCL1 in each sample was determined using a standard curve, as indicated by the kit.

Multiplex cytokines analysis was performed using tumor cell supernatants by human 71-cytokine /chemokine array panel kit (Milipore corporation, Burlington, MA, USA). Experimental and analytical steps were carried out at Eve technology corporation (Calgary, $\mathrm{AB}$, Canada).

\subsection{Immunostaining and Microscopy}

Cells $\left(1 \times 10^{4} /\right.$ well) were seeded in 96-well black glass bottom plates (Cellvis, Mountain View, CA, USA) and left untreated or treated with TNF- $\alpha(10 \mathrm{ng} / \mathrm{mL}, 15 \mathrm{~min})$ at a $70-80 \%$ confluency point. Cells were fixed with $2 \%$ PFA for $10 \mathrm{~min}$, permeabilized and blocked with $2 \%$ BSA in PBS- 1 X consisting of $0.1 \%$ triton X-100 for $1 \mathrm{~h}$ at room temperature. APC-conjugated NF-kB (14G10A21 Biovision, Milpitas, CA, USA), 1:400 diluted in blocking buffer) was incubated at $4{ }^{\circ} \mathrm{C}$ in humidified chamber overnight. Next day, they were washed twice with PBS-1x and subsequently incubated with NucBlue Live stain reagent for $1 \mathrm{~h}$ in the dark. Pictures were taken with an inverted Nikon TI2 microscope (Melville, NY, USA), LED light source ( Lumencor, Parkway Beaverton, OR, USA), and CMOS camera (prime 95B, Photometrics, Tucson, AZ, USA), and analyzed using Fiji imageJ software. 


\subsection{Cell-Survival Analysis}

Cell survival analysis was performed using cell titer-Glo ${ }^{\circledR} 2.0$ assay (Promega, Fittsburgh, MA, USA) according to instructions provided by company. Briefly, cells $\left(3 \times 10^{3} /\right.$ well) were seeded in 96-well microtiter plates and kept at $37^{\circ} \mathrm{C}$ in a $5 \% \mathrm{CO}$-incubator. Next day, cells were treated with serial dilution of vemurafenib $(16 \mu \mathrm{m}$ to $1 \mu \mathrm{m})$ or DMSO (control) for $48 \mathrm{~h}$ in incubator. Then, cells were exposed to cell titer-Glo ${ }^{\circledR} 2.0$ reagent for $10 \mathrm{~min}$ at RT, and the obtained luminescence value was measured by plate reader (BioTek Synergy/LX multimode reader). The relative cell survival analysis was calculated in relation to DMSO treated samples.

\subsection{Statistical Analysis of $q P C R$, Western Blots, Cell Survival and Cytokine Expression}

Statistical analysis was performed using GraphPad Prism 8.0.0 software (GraphPad software, Inc.). For comparative mRNA expression analysis of $\mathrm{p} 53^{\mathrm{WT}}$ vs. p53 ${ }^{\mathrm{ko}}$ by qPCR analysis, studies were conducted by biological quadruplicates and technical duplicate (if varies in biological samples, then it is mentioned in the figure legend). Cytokine analysis experiment was conducted in biological triplicate and technical duplicates. Western blot analysis was carried out in two independent experiments. Cell survival analysis was conducted in three independent experiments, and each experiment was carried out using technical quintuplicate $(n=5)$ wells, technical replicates were averaged, and biological replicates were used to compute statistics. Statistical differences between groups were determined using unpaired Student's $t$-test or ANOVA (one-way or two-way). $p<0.05$ was considered a statistically significant difference.

\section{Results}

\subsection{Melanoma Cell Lines Retain a Functional p53}

One hypothesis of why melanoma cells frequently retain wild type p53 is that they inactivated the p53 pathway by alternative mechanisms. To test this, we treated four common melanoma cell lines (LOX-IMVI, SK-MEL-5, UACC62 and UACC257) with DNAdamaging agents (UV and etoposide) or the non-genotoxic MDM2 inhibitor and p53 activator Nutlin-3A [29]. We observed in each cell line that p53 levels rose three hours after treatment for the etoposide and Nutlin-3A conditions and weakly for the UV treatment (Figure 1A). Though p53 levels rise in response to treatment, it is possible that p53 signaling in these models is defective for the transcriptional activation of key cell cycle arrest or pro-apoptosis target genes.

To more generally explore if p53 in melanoma cells can regulate a common set of p53 target genes, we used mRNA seq to monitor gene expression in each of the four cell lines after p53 activation by UV, etoposide, or Nutlin-3A. We identified those genes that were upregulated $(>1.5$-fold change, pval $<0.01)$ in all four cell lines in at least one condition $(n=85$, Figure $1 \mathrm{~B})$. Among these target genes, many are canonical p53 target genes, such as p21 (CDKN1A), MDM2, and NOXA (PMAIP1), including both pro-apoptotic and cell cycle arrest factors. Overall, the p53 pathway (Hallmark gene set) was strongly enriched in this set of overlapping upregulated genes (Figure 1C). Interestingly, our analysis also suggested that the NF-kB/TNF pathway was also induced by these treatments, as were apoptotic and epithelial-to-mesenchymal (EMT) signaling (Figure 1C). To visualize the extent to which these pathways are activated in each cell line, we generated gene set enrichment analysis (GSEA) plots for each treatment (Figure 1D etoposide treatment, and Figure S1A for Nutlin$3 a$ and UV treatments) for the p53 and NF-kB pathways. We observed strong enrichment for p53 signaling in each cell line, and enrichment of NF-kB/TNF signaling in each line in the majority of conditions (the LOX-IMVI line is not significant for the Nutlin-3A treatment, and the SK-Mel5 line is not significant for Nutlin-3a and UV treatment; Figure 1D, Figure S1A). We note that given the overlap between the NF-kB and p53 signatures (of the 200 genes in each set 26 are shared), disentangling the two pathways can be challenging informatically. We used qPCR to verify the activation of p53 target genes in each cell line and observed 
robust activation of p21 in all conditions and MDM2 in etoposide and Nutlin-3A treatment consistent with our RNAseq data (Figure 1E).

To test if these transcriptional effects are observed in normal cells as well as cancer models, we treated hTERT-immortalized melanocyte cells with the MDM2 inhibitor Nutlin3a. Using mRNAseq we observed strong activation of p53 signaling and also NF-kB targets (Figure S1B,C) in these non-cancerous melanocytes, suggesting conservation of this pathway beyond cancer.

To determine if p53 activity in vitro is related to human cancer models, we used mRNAseq gene expression data from the Pan-Cancer Atlas (TCGA) to compare human melanoma samples with wild type p53 to those with mutations in p53 [19,22]. We observed that compared to wild type cancers, p53 mutant melanomas show greatly reduced p53 signaling (Figure 1F) and reduced mRNA expression of the key p53 target gene p21 (CDKN1A, Figure 1G). These results argue that, as in cell culture in most melanomas which retain wild type $\mathrm{p} 53$, this protein/gene expression network is active.

\subsection{Loss of p53 in Melanoma Cell Lines Results in Reduced p53 and NF-kB Signaling}

To directly test the role of p53 in melanoma cells, we used Cas 9 to knockout p53 from the LOX-IMVI and SK-MEL-5 cell lines and derived clones from single cells (Figure 2A). We note a weak lower molecular weight band in one LOX-IMVI clone that could be a truncation product (clone \#2), however, our data suggest this clone is also a functional knockout. Using mRNAseq we compared three different $\mathrm{p} 53^{\mathrm{ko}}$ clones for their gene expression relative to wild type. Knockout of p53 produced reproducible changes in gene expression across the three clones, with 387 and 147 genes changing significantly ( $>0.5 \log 2$-fold change, $p$ value $<0.01$ ) in all clones from the LOX-IMVI and SK-MEL-5, respectively.

Enrichment analysis of the overlapping genes altered in the p53 knockout cells (Figure 2B) showed strong enrichment for p53 signaling and also NF-kB signaling (especially in the LOX-IMVI cells). Combined with our earlier results showing changes in NF-kB signaling in conditions that activate p53 (Figure 1), these results suggest that in the LOX-IMVI and SK-MEL-5 cell lines' loss of p53 results in a substantial change in NF-kB signaling.

To extend this analysis and identify commonalities between the two cell lines, we identified overlapping genes altered on p53 deletion. The genes altered in LOX-IMVI and SK-MEL-5 showed only modest, albeit significant, overlap $\left(p=1.09 \times 10^{-4}\right.$; hypergeometric test, applied to test the significance of overlap between two gene sets). Analyzing the 39 genes that were reduced, and one gene that was upregulated in at least $2 / 3$ clones in both cell lines we find that this overlap is enriched in both p53- and NF-kB-regulated genes. We also note the presence of certain genes (e.g., FN1—fibronectin) that are involved in EMT signaling (Figure 2C,D).

These results suggested that p53 loss might act on NF-kB signaling to induce noncanonical phenotypes. In melanoma, some of the key targets of NF-kB are immune modulatory cytokines. We therefore explored in a more targeted way using qPCR if we observed changes to key cytokines on p53 deletion in melanoma cell lines (Figure 2E). We used qPCR to look at the canonical p53 target gene p21, and a set of cytokines (CXCL1, LIF, CXCL8, IL1A, IL1B, WNT5A) in three p53 knockout clones of LOX-IMVI, SK-MEL-5, UACC62, and UACC257 (Figure 2A and Figure S2A). As we expected from our sequencing data, loss of p53 in each cell line resulted in reduced p21 expression, and also reduced expression of one or more of a heterogeneous set of cytokines (Figure 2E and Figure S2B). We note that reduced CXCL1 expression is universal across the four cell lines (except clone1 in LOX-IMVI cells, where the trend is down but non-significant). These results are consistent with a model whereby p53 loss reduces NF-kB signaling, with complex effects on individual $\mathrm{NF}-\mathrm{kB}$ target genes depending on the cell line context.

To further test the dependence of these effects on p53, we re-expressed p53 in the UACC 62 p53 $3^{\mathrm{ko}}$ cell line (Figure S2C) and observed a strong increase in p21 expression as expected, and a more modest increase in CXCL1, CXCL8, and LIF expression (Figure 2E). 
These results suggest that p53 regulates the expression of key cytokine genes in melanoma cell lines.

\section{3. p53 Loss Reduces Secretion of Cytokines}

To determine if the transcriptional loss of cytokine expression also occurs at the protein level, we employed a cytokine array that measured the levels of 71 cytokines in supernatant harvested from equivalent numbers of $\mathrm{p} 53^{\mathrm{WT}}$ or $\mathrm{p} 53^{\mathrm{ko}}$ LOX-IMVI cells. Fifty-two out of seventy-one ligands were observed in detection range in p53 ${ }^{\mathrm{WT}}$ LOX-IMVI cells. These ligands are arranged in decreasing concentration range, i.e., $>10,1-10$, and $<10 \mathrm{pg} / \mathrm{mL}$ (Figure 3A). Testing three different knockout cell lines, we observed significant reductions of many key cytokines that mirrored our observations in mRNAseq (Figure 3A).

A Observed Conc. in p53 ${ }^{\mathrm{WT}}$ cells $(\mathrm{pg} / \mathrm{ml})$

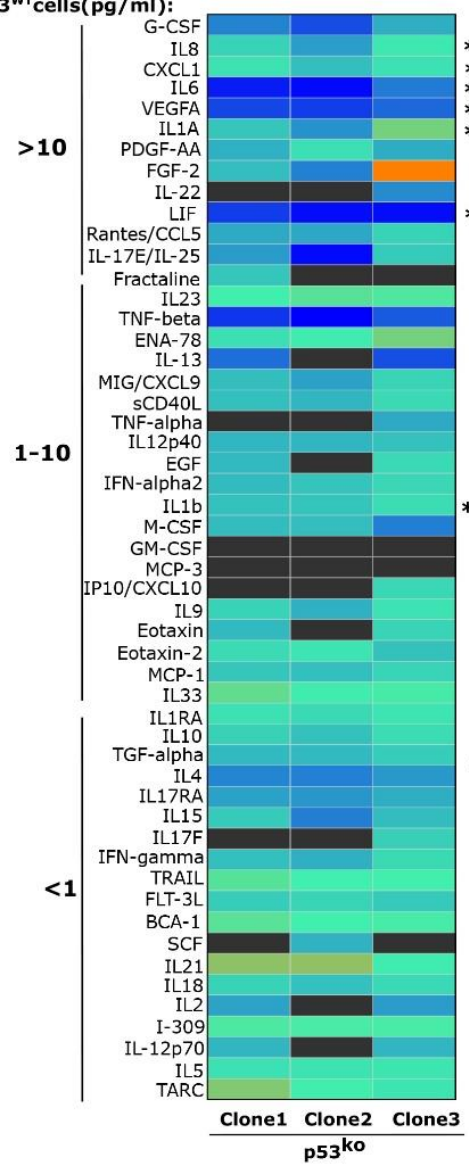

B

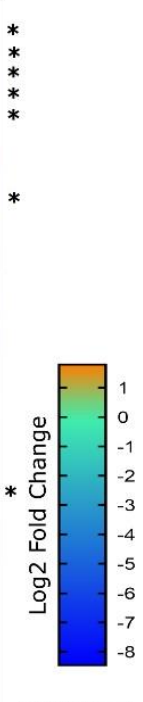

$<$ detection range
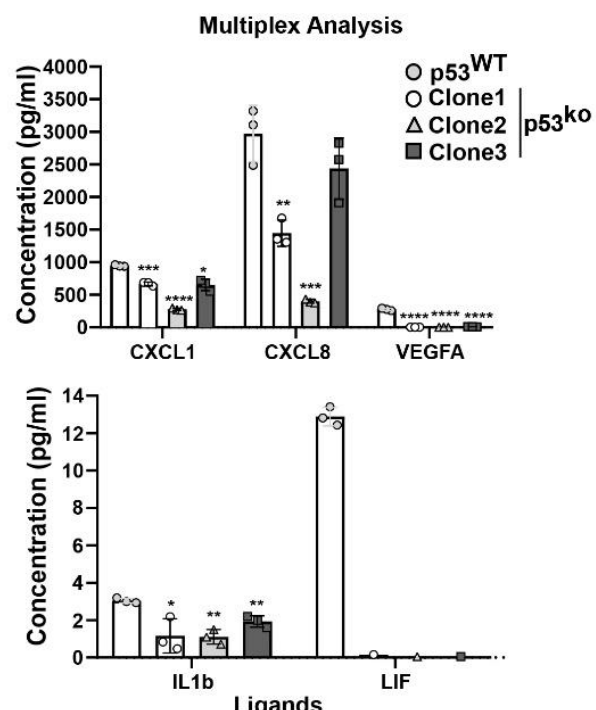

$c$

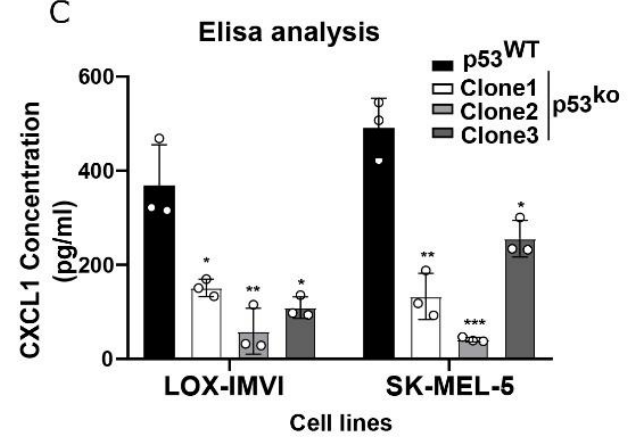

Figure 3. Reduced cytokine secretion in p53 knockout melanoma lines. (A) Comparative analysis of ligands abundance in supernatant from $\mathrm{p} 53^{\mathrm{ko}}$ and $\mathrm{p} 53^{\mathrm{WT}}$ LOX-IMVI cells by multiplex cytokine array. Differential expression of secreted ligand for each knockout clone compared to wild type is shown in the heatmap (as in log2-fold change). The observed ligand concentration $(\mathrm{pg} / \mathrm{mL})$ in $\mathrm{p} 53^{\mathrm{WT}}$ cells are depicted on the right side by numbers $>10,1-10$, and $<1$. Cytokines analyzed by qPCR (in Figures $2 \mathrm{E}$ and $4 \mathrm{E}$ ) are indicated by an asterisk on the left side. (B) Expression of a subset of the ligands in wild-type and knockout clones by multiplex analysis is demonstrated. $n=3$ (mean \pm S.D), except for LIF, in which two biological samples had shown the value below the detection limit. (C) Validation of CXCL1 expression in p53 ${ }^{\mathrm{ko}}$ LOX-IMVI and SK-MEL-5 cells by Elisa analysis; $n=3$ (mean \pm S.D). Significance was determined by $t$-test in comparison to the wild-type group, and the observed level of significance is shown by asterisk ${ }^{*}<0.05 ; * *<0.005$; ${ }^{* * *}$ $\left.<0.0005 ;{ }^{* * * *}<0.0001\right)$. 
A

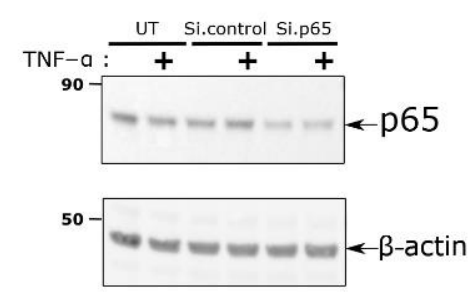

B

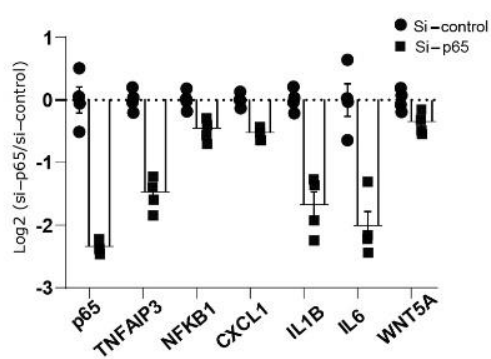

C

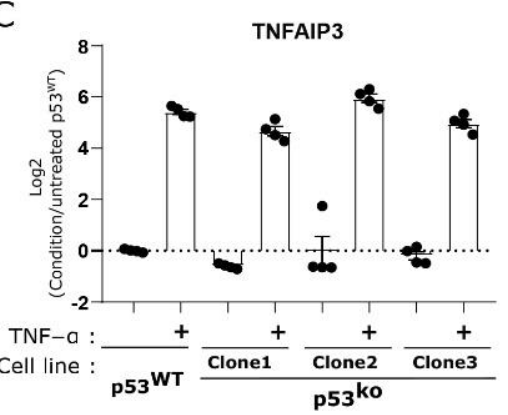

D

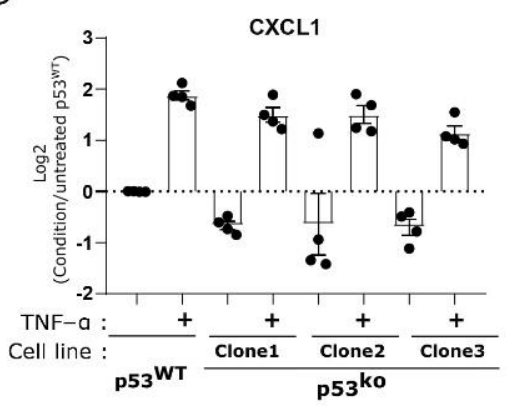

E

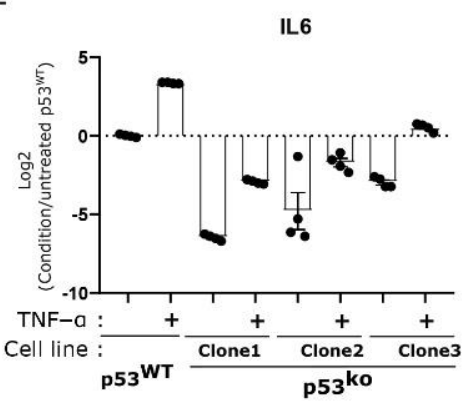

$\mathrm{F}$

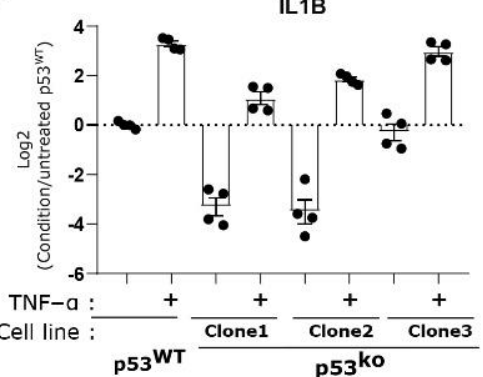

G

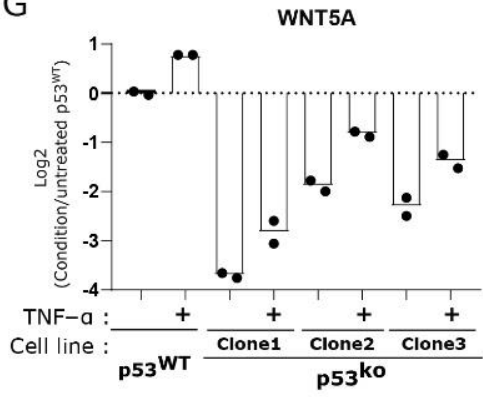

$\mathrm{H}$

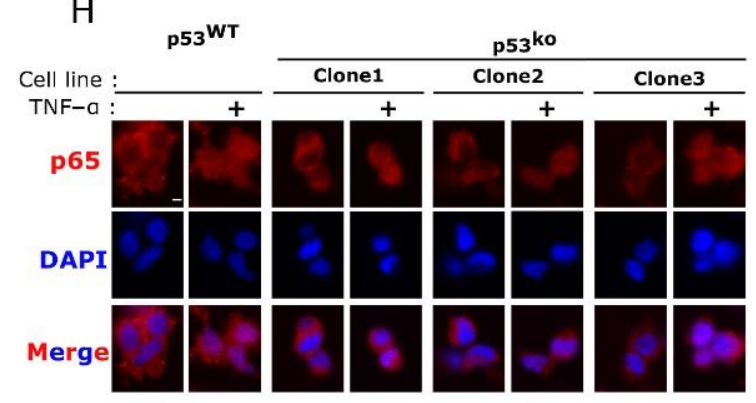

Figure 4. NF-kB activation by TNF-alpha and regulation of cytokine expression does not depend on p53. (A) si-RNA-mediated p65 knockdown validated by Western blot analysis. (B) qPCR analysis of NF-kB target genes in p65 knockdown LOX-IMVI cells. (C-G) p53 ${ }^{\mathrm{WT}}$ and $\mathrm{p} 53^{\mathrm{ko}}$ cells were stimulated with $10 \mathrm{ng} / \mathrm{mL}$ TNF-alpha for $2 \mathrm{~h}$, followed by qPCR analysis, focusing on specific sets of NF-kB target genes, TNFAIP3 (C), CXCL1 (D), IL6 (E), IL1B (F), and WNT5A (G). (H) Analysis of p65 expression in $\mathrm{p}^{\mathrm{k}} 3^{\mathrm{ko}}$ and $\mathrm{p} 53^{\mathrm{WT}}$ LOX-IMVI cells stimulated with $10 \mathrm{ng} / \mathrm{mL}$ TNF- $\alpha$ for $15 \mathrm{~min}$, using immunofluorescence. The bar graph in $(\mathbf{B}-\mathbf{G})$ is representing the mean \pm S.E.M. of four $(\mathbf{B}-\mathbf{F})$ or two (G) biological repeats. Each circle or square dot is representing an individual biological sample. Scale bar in $(\mathbf{H})$ is equal to $5 \mu \mathrm{m}$.

For example, CXCL1, IL1, LIF, and VEGFA were all significantly reduced (between $\sim 2$-fold for CXCL1, and >10-fold for LIF and VEGFA, Figure 3B). To validate this reduced cytokine expression, we ran an Elisa for CXCL1 on supernatant from the LOX-IMVI and SK-MEL-5 cell lines and observed in both models p53 ${ }^{\mathrm{ko}}$ clones showed reduced 
expression of CXCL1 (Figure 3C), consistent with our array and RNA measurements (Figures $2 \mathrm{C}$ and $3 \mathrm{~A})$.

\subsection{Key Cytokines Reduced by p53 Loss Are Regulated by NF-kB}

Our sequencing analysis pointed to a potential role for NF-kB downstream of p53. Using the LOX-IMVI cell line as our model, we tested the regulation of cytokines such as CXCL1 by NF-kB. Using siRNA against the NF-kB (RelA) we observed a loss of NF-kB protein (Figure 4A), and reduced expression of CXCL1 and IL1, confirming the regulation of these targets by NF-kB in this system (Figure 4B).

If $\mathrm{p} 53$ loss results in a hard block to NF-kB expression, then we would expect activation of NF-kB by TNF would be attenuated. We therefore treated the $\mathrm{p} 53^{\mathrm{WT}}$ and $\mathrm{p} 53^{\mathrm{ko}} \mathrm{LOX}$ IMVI cell lines with TNF- $\alpha$ to activate NF-kB signaling. We observed that the $p 53^{\mathrm{ko}}$ and p53 ${ }^{\mathrm{WT}}$ cells showed a comparable increase in gene expression for the canonical NF-kB target TNFAIP3 (Figure 4C). For cytokines such as CXCL1 where we observed reduced expression in $\mathrm{p} 53^{\mathrm{ko}}$ cells, treatment with TNF- $\alpha$ induced these target genes to similar (CXCL1, IL1B) or somewhat lower (IL6, WNT5A) levels compared to wild type (Figure 4D-G). We also observed relatively little change in the abundance and localization of the p65 protein in the p53 knockout cell lines Figure $4 \mathrm{H}$ and Figure S3). This suggests that loss of p53 reduces basal NF-kB signaling, without altering its ability to be activated by external signals.

Previously it was suggested that p53 regulated or was regulated by Wnt5a, which drove many of the p53 associated phenotypes in melanoma [8]. Though we do observe loss of Wnt5a expression in 2/4 of our cell lines, including the LOX-IMVI line (Figure 2E), knockdown of Wnt5a does not reduce CXCL1 expression (Figure S4A). Further, the addition of recombinant Wnt5a does not result in increased cytokine expression in the LOX-IMVI p53 ${ }^{\mathrm{ko}}$ cell lines (Figure S4B,C). These results suggest that Wnt5a is not playing a major role in the phenotypes we observe.

\subsection{Loss of p53 Results in Reduced Cell Migration and Sensitivity to BRAF Inhibitor}

Cytokines are critical for driving cell migration and specifically CXCL1 has previously been shown to regulate cell movement [30]. We used a transwell assay to determine if loss of p53-driven cytokines affected cell migration. Supernatant from p53 ${ }^{\mathrm{WT}}$ LOX-IMVI cells could attract cancer cells through the transwell (Figure 5A,B), whereas supernatant from $\mathrm{p} 53^{\mathrm{ko}}$ cell lines showed reduced ability to drive cells through a transwell that was statistically indistinguishable from media. These results show that tumor cell migration is reduced in the context of the p53 ${ }^{\mathrm{ko}}$ secretome.

To test if the change in these results holds for immune cell migration, we repeated the experiment with the human monocyte line U937. As with the cancer cells, we observed that monocyte migration in a transwell was strongly promoted by wild type, but not $\mathrm{p} 53^{\mathrm{ko}}$ LOX-IMVI conditions media (Figure 5C).

Given that autocrine and paracrine signaling can be critical to driving resistance to certain therapeutic agents, we hypothesized that p53 knockout cells might be more sensitive to common therapeutic modalities. Indeed, previous work showed that the ability of p53 to block the cell cycle could promote survival in melanoma cells treated with DNA damaging therapies [8]. We therefore sought to test if loss of p53 would increase the sensitivity of LOX-IMVI cells to BRAF inhibitors which are commonly used to treat melanomas. Despite having a BRAF ${ }^{\mathrm{V} 600 \mathrm{E}}$ allele, LOX-IMVI cells are highly resistant to the BRAF inhibitor vemurafenib [31,32]. We observed that $\mathrm{p} 53^{\mathrm{WT}}$ LOX-IMVI cells show a little reduction of ERK phosphorylation when treated with vemurafenib (BRAF inhibitor) for 24 h; however, the $\mathrm{p} 53^{\mathrm{ko}}$ lines show reductions in ERK phosphorylation when treated with the same dose (Figure 6A). Consistent with reduced ERK activity, we observed that the p53 ${ }^{\mathrm{ko}}$ clones are more sensitive towards vemurafenib treatment as measured by cell titer-Glo (Figure 6B). We also noted a marked morphological change in the $\mathrm{p} 53^{\mathrm{ko}}$ cell lines upon treatment with vemurafenib that is absent in the wild type cells (Figure S5). 

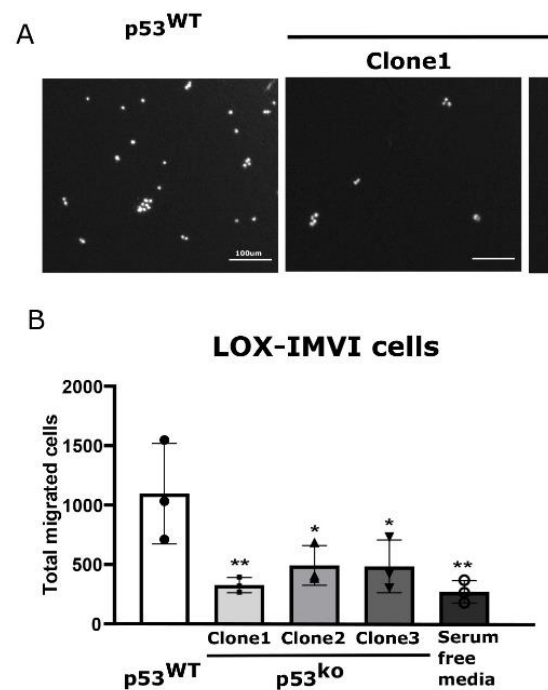

p53ko

Clone2

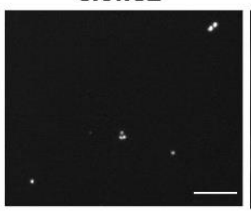

C

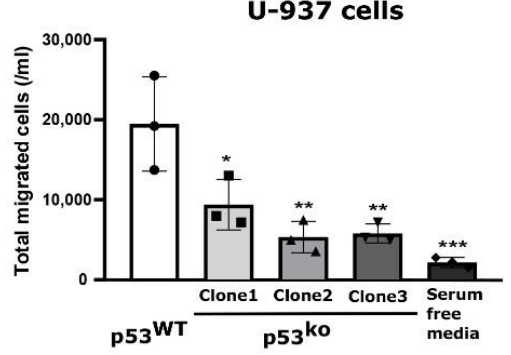

Figure 5. Supernatant from p53 knockout melanoma shows reduced chemoattractant properties. (A) A representative transwell image of migrated LOX-IMVI cells in response to $\mathrm{p} 53^{\mathrm{WT}}$ vs. p53 ${ }^{\mathrm{ko}}$ supernatant. (B,C) The total migrated LOX-IMVI (B) and U-937 (C) cells through transwell in response to supernatant is shown by bar graph. $n=3$, mean \pm S.D. for $(\mathbf{B}, \mathbf{C})$; significance assessed by one-way ANOVA relative to the $\mathrm{p} 53^{\mathrm{WT}}$ group. The observed significance level is shown by asterisk $\left({ }^{*}<0.05 ;{ }^{* *}<0.005 ; * * * 0.0005\right)$. Scale bar in $(\mathbf{A})$ is equal to $100 \mu \mathrm{m}$.

A

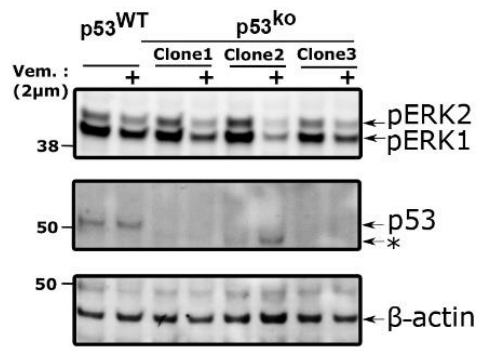

B

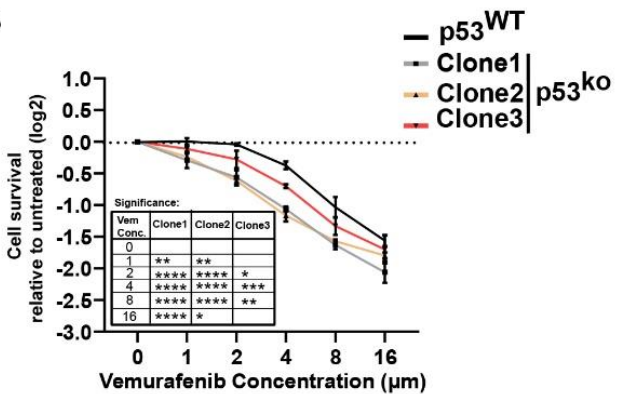

C

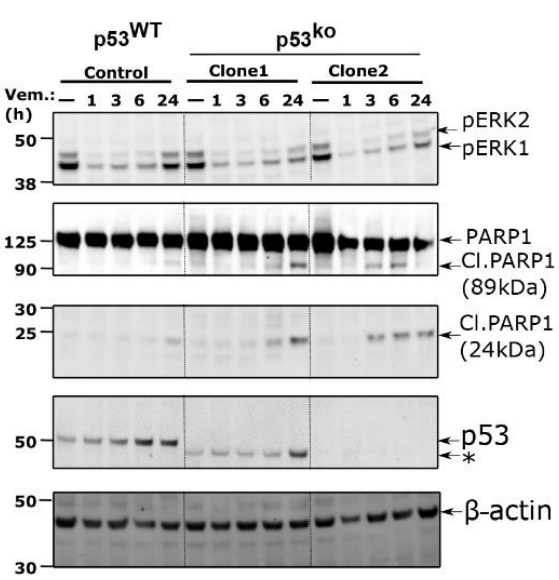

Figure 6. p53 loss in LOX-IMVI cells increases sensitivity towards vemurafenib. (A) Western blot for pERK abundance in LOX-IMVI cells exposed to vemurafenib $(2 \mu \mathrm{M}, 24 \mathrm{~h})$. (B) Cell viability analysis of $\mathrm{p} 53^{\mathrm{WT}}$ and $\mathrm{p} 53^{\mathrm{ko}}$ LOX-IMVI cells after exposure to the indicated dose of vemurafenib for $48 \mathrm{~h}$ by CellTiter-Glo. Change in cellular viability (in log2-fold) relative to untreated cells is shown by line graph ( $n=3$, mean \pm S.D.). Significance was assessed by two-way ANOVA relative to $\mathrm{p} 53^{\mathrm{WT}}$ group, and the significance level is shown in the inserted table by asterisk $\left(^{*}<0.05{ }^{* *}<0.005 ;{ }^{* * *}<0.0005\right.$; $* * * *<0.0001)$. (C) p53 $3^{\mathrm{WT}}$ and $\mathrm{p} 53^{\mathrm{ko}}$ LOX-IMVI cell treated with $2 \mu \mathrm{M}$ vemurafenib for indicated time points and $\mathrm{pERK}$, PARP1 full length and cleavage product abundance measured by immunoblot. Asterisk $\left(^{*}\right)$ in $(\mathbf{A})$ and $(\mathbf{C})$, denotes the lower molecular weight band (as demonstrated in Figure 2A) in one of the LOX-IMVI clones. 
To explore the nature of this sensitivity more fully, we compared p53 ${ }^{\mathrm{WT}}$ and $\mathrm{p} 53^{\mathrm{ko}}$ cells at $1,3,6$, and $24 \mathrm{~h}$ after vemurafenib treatment $(2 \mu \mathrm{M})$. We observed that both genotypes have reduced pERK expression after $1 \mathrm{~h}$ however, pERK expression level rebounds in $\mathrm{p} 53^{\mathrm{WT}}$ cells to nearly basal levels at $24 \mathrm{~h}$, while it remains suppressed in the p53 ${ }^{\mathrm{ko}}$ lines (Figure 6C). In these conditions we also observe the presence of cleaved PARP1 in the p53 $3^{\mathrm{ko}}$ cell line, which is an early marker of apoptosis [33,34].

\section{Discussion}

Melanoma is unusual among solid tumors for its low rate of p53 mutations, which is especially surprising given its high UV-induced mutation rate. Other groups have suggested that p53 may provide some benefit to a developing melanoma by regulating the cell cycle through Wnt signaling [8]. Here we used unbiased profiling to identify cytokine regulation as significantly altered in multiple melanoma cell lines where we induce p53 loss.

In the present study, using four different human melanoma cell-lines that possess wild type p53, we found the p53 is functionally active in these lines by demonstrating p53 activation and induce expression of p53 target gene expression in response to DNA-damage agents (UV or etoposide) or by Nutlin-3A, a specific p53 activator [29]. Further, our gene expression data suggested a potential role for p53 in the regulation of NF-kB target genes, consistent with the earlier observation from our group that used ChIPseq to show p53 DNA binding at CXCL1 in the LOX-IMVI cell lines. To decipher the role of p53 in melanoma, we performed transcriptome analysis in control and p53 knockout melanoma cells. In addition to a loss of canonical p53 transcription, we also identified a general reduction in many NF$\mathrm{kB}$ target genes including cytokines at both the RNA and protein level. A linkage between p53 and cytokine expression is also observed in fibroblast [10] and macrophage cells [11].

Pro-inflammatory cytokines/chemokines are strongly regulated throughout melanoma development. For example, overexpression of CXCL1 is involved in primary cancer development and also during metastasis by promoting angiogenesis [35]. Additionally, work with mouse models of melanoma has also shown that inflammatory signaling is a strong promoter of metastasis in UV-induced melanoma [36].

Though we observed dampened expression of NF-kB target genes in p53-deficient melanoma cells, TNF- $\alpha$ treatment activates NF-kB and increases the expression of its target genes in melanoma cell lines regardless of p53 status. These results suggest that p53 regulates the basal activity of NF-kB but is not intrinsically required for its activation. Previous studies have shown that these two transcription factors interact to execute their functions. For example, NF-kB regulated expression of NOXA and p53AIP1 is required for p53-mediated cellular apoptosis in some cases [37,38]. Additionally, p53 is an indispensable component for stimulation of classical and atypical NF-kB target genes during replication stress [39]. In human macrophages, these transcription factors cooperate to induce pro-inflammatory cytokines and chemokines, including CXCL1, IL-6, and CXCL8 [11]. However, the exact dependency between NF-kB and p53 to regulate cytokine expression in melanoma remains unclear.

We show that the loss of p53 alters two cytokine-dependent phenotypes, chemotaxis and growth factor signaling. Knockdown of p53 in melanoma can reduce melanoma growth [40], which is contrary to its conventional tumor-suppressive role. Our study suggests one potential mechanism for this surprising observation by showing that wildtype p53 can modulate the expression of cytokines, including inflammatory and immune regulators in melanoma cells. These results dovetail with expanding literature on the non-DNA damage roles of p53 in cancer. For some cancers, the benefits of p53 loss in tolerance of mutation and higher proliferative rates may be offset by the loss of non-canonical p53-dependent pathways. 
Supplementary Materials: The following supporting information can be downloaded at https:// www.mdpi.com/article/10.3390/cells11030405/s1: Figure S1: Activation of p53 results in expression of p53 and NF-kB target genes; Figure S2: Presence of p53 regulates cytokine expression; Figure S3: Expression of p65 is not regulated by p53; Figure S4: Wnt5a does not rescue the expression of cytokine in p53ko LOX-IMVI cells; Figure S5: BRAF inhibition results in morphological changes to p53ko cells. Table S1 contains source data for all figures.

Author Contributions: Data were collected by L.K., P.P., and J.S.-O. Data were analyzed, and figures prepared by P.P. and J.S.-O. The manuscript was prepared by P.P. and J.S.-O. with input from L.K. All authors have read and agreed to the published version of the manuscript.

Funding: Funding for this study was from the Hillman Cancer Center and the NCI CA207727-04 (to JSO).

Institutional Review Board Statement: Not applicable.

Informed Consent Statement: Not applicable.

Data Availability Statement: RNAseq data is deposited at GEO (GSE182570,). Other relevant data is included within the manuscript, source data, and supplementary materials.

Acknowledgments: We thank the Cancer Genomics Facility at the Hillman Cancer Center, and its director, Maureen Lyons, for help with sequencing. We also thank Shayla Goller and Kyle Davidson for comments on the study. We thank Yi-Nan Gong, Man-Tzu Wang and Ben Van Houten for helpful discussions.

Conflicts of Interest: The authors declare no conflict of interest.

\section{References}

1. Liu, J.; Zhang, C.; Feng, Z. Tumor suppressor p53 and its gain-of-function mutants in cancer. Acta Biochim. Biophys. Sin. 2014, 46, 170-179. [CrossRef]

2. Zehir, A.; Benayed, R.; Shah, R.H.; Syed, A.; Middha, S.; Kim, H.R.; Srinivasan, P.; Gao, J.; Chakravarty, D.; Devlin, S.M.; et al. Mutational landscape of metastatic cancer revealed from prospective clinical sequencing of 10,000 patients. Nat. Med. 2017, 23, 703-713. [CrossRef]

3. Hodis, E.; Watson, I.R.; Kryukov, G.V.; Arold, S.T.; Imielinski, M.; Theurillat, J.-P.; Nickerson, E.; Auclair, D.; Li, L.; Place, C.; et al. A landscape of driver mutation in melanoma. Cell 2012, 150, 251-263. [CrossRef]

4. $\quad$ Essner, R.; Kuo, C.T.; Wang, H.; Wen, D.R.; Turner, R.R.; Nguyen, T.; Hoon, D. Prognostic implications of p53 overexpression in cutaneous melanoma from sun-exposed and nonexposed sites. Cancer 1998, 82, 309-316. [CrossRef]

5. Kim, D.W.; Haydu, L.E.; Joon, A.; Bassett, R.L.; Siroy, A.E.; Tetzlaff, M.T.; Routbort, M.J.; Amaria, R.N.; Wargo, J.A.; McQuade, J.L.; et al. Clinicopathological features and clinical outcomes associated with TP53 and BRAFNon-V600 mutations in cutaneous melanoma patients. Cancer 2017, 123, 1372-1381. [CrossRef]

6. Li, F.P.; Fraumeni, J.F., Jr. Soft-tissue sarcomas, breast cancer, and other neoplasms. A familial syndrome? Ann. Int. Med. 1969, 71, 747-752. [CrossRef]

7. Bougeard, G.; Renaux-Petel, M.; Flaman, J.-M.; Charbonnier, C.; Fermey, P.; Belotti, M.; Gauthier-Villars, M.; Stoppa-Lyonnet, D.; Consolino, E.; Brugières, L.; et al. Revisiting Li-Fraumeni Syndrome From TP53 Mutation Carriers. J. Clin. Onco. 2015, 33, 2345-2352. [CrossRef]

8. Webster, M.R.; Fane, M.E.; Alicea, G.M.; Basu, S.; Kossenkov, A.V.; Marino, G.E.; Douglass, S.M.; Kaur, A.; Ecker, B.L.; Gnanapradeepan, K.; et al. Paradoxical role for Wild-type p53 in driving therapy resistance in melanoma. Mol. Cell 2020, 77, 1-12. [CrossRef]

9. Hafner, A.; Kublo, L.; Tsabar, M.; Lahav, G.; Stewart-Ornstein, J. Identification of universal and cell-type specific p53 DNA binding. BMC Mol. Cell Biol. 2020, 21, 5. [CrossRef]

10. Arandkar, S.; Furth, N.; Elisha, Y.; Nataraj, N.B.; van der Kuip, H.; Yarden, Y.; Aulitzky, W.; Ulitsky, I.; Geiger, B.; Oren, M. Altered p53 functionality in cancer-associated fibroblasts contributes to their cancer-supporting features. Proc. Natl. Acad. Sci. USA 2018, 115, 6410-6415. [CrossRef]

11. Lowe, J.M.; Menendez, D.; Bushel, P.R.; Shatz, M.; Kirk, E.L.; Troester, M.A.; Garantziotis, S.; Fessler, M.B.; Resnick, M.A. p53 and NF-kB Co-regulate Pro-inflammatory Gene Responses in Human Macrophages. Cancer Res. 2014, 74, 2182-2192. [CrossRef]

12. Herrero, A.B.; Rojas, E.A.; Misiewicz-krzemiska, I.; Krzeminski, P.; Gutierrez, N.C. Molecular mechanism of p53 deregulation in Cancer: An overview in multiple myeloma. Int. J. Mol. Sci. 2016, 17, 2003. [CrossRef]

13. Rivlin, N.; Brosh, R.; Oren, M.; Rotter, V. Mutation in the p53 tumor suppressor gene. Important milestones at the various steps of tumorigenesis. Genes Cancer 2011, 4, 466-474. [CrossRef]

14. Kim, S.; You, D.; Jeong, Y.; Yoon, S.Y.; Kim, S.A.; Kim, S.W.; Nam, S.J.; Lee, J.E. WNT5A augments cell invasiveness by inducing CXCL8 in HER2-positive breast cancer cells. Cytokine 2020, 135, 155213. [CrossRef] 
15. Xu, G.; Wang, H.; Li, W.; Xue, Z.; Luo, Q. Leukemia inhibitory factor inhibits the proliferation of gastric cancer by inducing G1-phase arrest. J. Cell Physiol. 2019, 234, 3613-3620. [CrossRef]

16. Ishigami, K.; Nosho, K.; Koide, H.; Kanno, S.; Mitsuhashi, K.; Igarashi, H.; Shitani, M.; Motoya, M.; Kimura, Y.; Hasegawa, T.; et al. MicroRNA-31 reflects IL-6 expression in cancer tissue and is related with poor prognosis in bile duct cancer. Carcinogenesis 2018, 39, 1127-1134. [CrossRef]

17. Zeng, A.; Yin, J.; Li, Y.; Li, R.; Wang, Z.; Zhou, X.; Jin, X.; Shen, F.; Yan, W.; You, Y. miR-129-5p targets Wnt5a to block PKC/ERK/NF-kB and JNK pathways in glioblastoma. Cell Death Dis. 2018, 9, 394. [CrossRef]

18. Zhou, A.; Scoggin, S.; Gaynor, R.B.; William, N.S. Identification of NF-kb regulatied genes induced by TNFalpha utilizing expression profiling and RNA interference. Oncogene 2003, 22, 2054-2064. [CrossRef]

19. Hoadley, K.A.; Yau, C.; Hinoue, T.; Wolf, D.M.; Lazar, A.J.; Drill, E.; Shen, R.; Taylor, A.M.; Cherniack, A.D.; Thorsson, V. Cell-of-Origin Patterns Dominate the Molecular Classification of 10,000 Tumors from 33 Types of Cancer. Cell 2018, 173, 291-304. [CrossRef]

20. Cerami, E.; Gao, J.; Dogrusoz, U.; Gross, B.E.; Sumer, S.O.; Aksoy, B.A.; Jacobsen, A.; Byrne, C.J.; Heuer, M.L.; Larsson, E.; et al. The cBio cancer genomics portal: An open platform for exploring multidimensional cancer genomics data. Cancer Discov. 2012, 2, 401-404. [CrossRef]

21. Gao, J.; Aksoy, B.A.; Dogrusoz, U.; Dresdner, G.; Gross, B.; Sumer, S.O.; Sun, Y.; Jacobsen, A.; Sinha, R.; Larsson, E.; et al Integrative analysis of complex cancer genomics and clinical profiles using the cBioPortal. Sci. Signal. 2013, 6, pl1. [CrossRef]

22. The Cancer Genome Atlas Network. Genomic Classification of Cutaneous Melanoma. Cell 2015, 161, 1681-1696. [CrossRef]

23. Lim, W.K.; Lyashenko, E.; Califano, A. Master regulators used as breast cancer metastasis classifier. Pac. Symp. Biocomput. 2009, 14, 504-515.

24. Patro, R.; Duggal, G.; Love, M.I.; Irizarry, R.A.; Kingsford, C. Salmon provides fast and bias-aware quantification of transcript expression. Nat. Methods 2017, 14, 417-419. [CrossRef] [PubMed]

25. Love, M.I.; Huber, W.; Anders, S. Moderated estimation of fold change and dispersion for RNA-seq data with DESeq2. Genome Biol. 2014, 15, 550. [CrossRef]

26. Gene Set Enrichment Analysis. Molecular Signatures Database. Available online: https://www.gsea-msigdb.org/gsea/msigdb/ (accessed on 1 August 2021).

27. Mootha, V.K.; Lindgren, C.M.; Eriksson, K.F.; Subramanian, A.; Sihag, S.; Lehar, J.; Puigserver, P.; Carlsson, E.; Ridderstråle, M.; Laurila, E.; et al. PGC-1a-responsive genes involved in oxidative phosphorylation are coordinately downregulated in human diabetes. Nat. Genet. 2003, 34, 267-273. [CrossRef]

28. Subramanian, A.; Tamayo, P.; Mootha, V.K.; Mukherjee, S.; Ebert, B.L.; Gillette, M.A.; Paulovich, A.; Pomeroy, S.L.; Golub, T.R.; Lander, E.S.; et al. Gene set enrichment analysis: A knowledge-based approach for interpreting genome-wide expression profiles. Proc. Natl. Acad. Sci. USA 2005, 102, 15545-15550. [CrossRef]

29. Vassilev, L.T.; Vu, B.T.; Graves, B.; Carvajal, D.; Podlaski, F.; Filipovic, Z.; Kong, N.; Kammlott, U.; Lukacs, C.; Klein, C.; et al. In vivo activation of the p53 pathway by small-molecule antagonist of MDM2. Science 2004, 303, 844-848. [CrossRef]

30. Acharyya, S.; Oskarsson, T.; Vanharanta, S.; Malladi, S.; Kim, J.; Morris, P.G.; Manova-Todorova, K.; Leversha, M.; Hogg, N.; Seshan, V.E.; et al. A CXCL1 paracrine network links cancer chemoresistance and metastasis. Cell 2012, 150, 165-178. [CrossRef]

31. Konieczkowski, D.J.; Johannessen, C.M.; Abudayyeh, O.; Kim, J.W.; Cooper, Z.A.; Piris, A.; Frederick, D.T.; Barzily-Rokni, M.; Straussman, R.; Haq, R.; et al. A melanoma cell state distinction influences sensitivity to MAPK pathway inhibitors. Cancer Discov. 2014, 4, 816-827. [CrossRef]

32. Orgaz, J.L.; Crosas-Molist, E.; Sadok, A.; Perdrix-Rosell, A.; Maiques, O.; Rodriguez-Hernandez, I.; Monger, J.; Mele, S.; Georgouli, M.; Bridgeman, V.; et al. Myosin II reactivation and cytoskeletal remodeling as a hallmark and a vulnerability in melanoma therapy resistance. Cancer Cell 2020, 37, 85-103. [CrossRef]

33. Germain, M.; Affar, E.B.; D’Aamours, D.; Dixit, V.M.; Salvesen, G.S.; Poirier, G.G. Cleavage of automodified poly(ADP-ribose) polymerase during apoptosis. Evidence for involvement of caspase-7. J. Biol. Chem. 1999, 74, 28379-28384. [CrossRef]

34. Kaufmann, S.H.; Desnoyers, S.; Ottaviano, Y.; Davidson, N.E.; Poirier, G.G. Specific proteolytic cleavage of poly(ADP-ribose) polymerase: An early marker of chemotherapy-induced apoptosis. Cancer Res. 1993, 53, 3976-3985.

35. Dhawan, P.; Richmond, A. Role of CXCL1 in tumorigenesis of melanoma. J. Leukoc. Biol. 2002, 72, 9-18.

36. Bald, T.; Quast, T.; Landsberg, J.; Rogava, M.; Glodde, N.; Lopez-Ramos, D.; Kohlmeyer, J.; Riesenberg, S.; Van Den BoornKonijnenberg, D.; Hömig-Hölzel, C.; et al. Ultraviolet-radiation-induced inflammation promotes angiotropism and metastasis in melanoma. Nature 2014, 507, 109-113. [CrossRef]

37. Ryan, K.M.; Ernst, M.K.; Rice, N.R.; Vousden, K.H. Role of NF-kb in p53-mediated programmed cell death. Nature 2000, 404 , 892-897. [CrossRef]

38. Pavlakis, E.; Stiewe, T. p53's extended reach: The mutant p53 secretome. Biomolecules 2020, 10, 307. [CrossRef]

39. Schneider, G.; Henrich, A.; Greiner, G.; Wolf, V.; Lovas, A.; Wieczorek, M.; Wagner, T.; Reichardt, S.; Von Werder, A.; Schmid, R.M.; et al. Cross talk between stimulated NF-kb and the tumor suprressor p53. Oncogene 2010, 29, 2795-2806. [CrossRef]

40. Avery-Kiejda, K.A.; Bowden, N.A.; Croft, A.J.; Scurr, L.L.; Kairupan, C.F.; Ashton, K.A.; Talseth-Palmer, B.A.; Rizos, H.; Zhang, X.D.; Scott, R.J.; et al. p53 in human melanoma fails to regulate target genes associated with apoptosis and the cell cycle and may contribute to proliferation. BMC Cancer 2011, 11, 203. [CrossRef] 